\title{
Study on the Causes and Countermeasures of Power Loss of Photovoltaic Modules
}

\author{
Zuo Yan ${ }^{1}$, Dong Peng ${ }^{1}$ \\ ${ }^{1}$ SPIC Solar Power Xi'an Co., LTD, 396 3rd Yannan Road Xi'an, China
}

\begin{abstract}
In this paper, major causes of photovoltaic modules power lose are divided into two basic categories during encapsulation, the optical power lose and electrical power lose. The effect of encapsulating materials on the power lose of photovoltaic modules is analyzed by comparative test. The result shows that these some encapsulating materials have a great effect on the photovoltaic power loss. Calculation of electrical power loss is carried out in this paper. It is shown that the power loss of the interconnection solder ribbon plays a dominant role in electrical power loss.
\end{abstract}

\section{Introduction}

Photovoltaic (hereinafter referred to as PV) power generation has become one of the mainstreams of green energy application technology in recent years. Low cost, high efficiency and long working life are the three major objectives, which have been pursued for decades in PV industry. The power of PV module plays a major role in the achievement of these objectives. So the control and reduction measures of power loss of PV module during encapsulation and service process become a hotspot concerned by the whole industry.

In theory, the power output of PV module after encapsulation is the sum of the power output of all solar cells, while actually it is generally smaller than the power output of all solar cells. The difference is called encapsulated power loss of PV module. The encapsulated power loss is usually about $3 \%$ to $4 \%$ [1] and can be divided into two categories, the optical power loss and the electrical power loss. In this paper, the major causes of encapsulated power lose of PV module and its countermeasures are studied.

\section{Main contents}

\subsection{Design principle of PV module}

PV module is consisted of a certain amount of solar cells, which are connected in series and parallel mode. Then it is encapsulated to module with certain output voltage and current by PV encapsulating materials. PV module is usually consisted of tempered glass, ethylene-vinylacetate adhesive film (hereinafter referred to as EVA), solar cell strings (solar cells connected with solder ribbons), EVA and back sheet from top to bottom. The encapsulation structure and electrical principle diagram of PV module with 60 polycrystalline solar cells is shown in Fig. 1 and Fig.2 respectively.

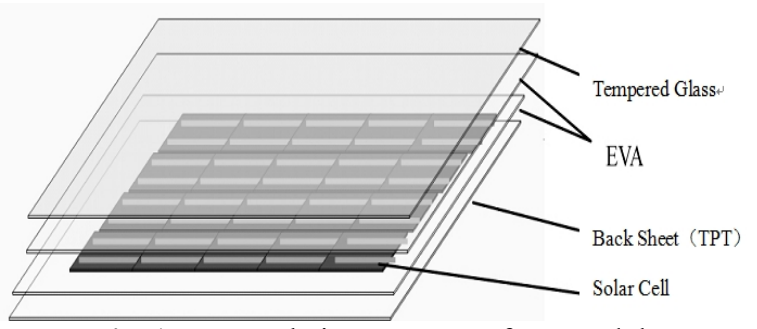

Fig. 1. Encapsulation structure of PV module

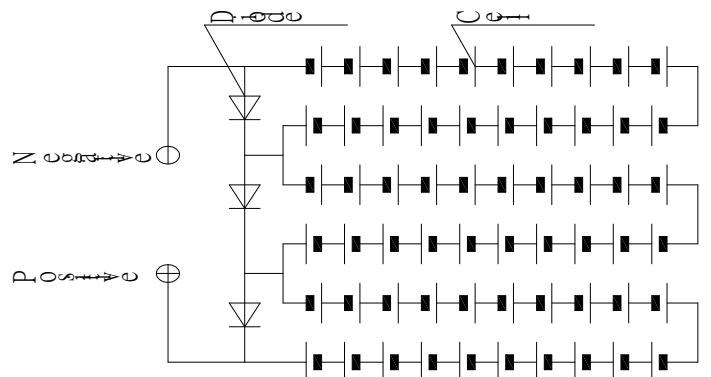

Fig. 2. Electrical principle diagram of PV module

\subsection{Optical power loss during encapsulation}

The response spectra range of crystalline silicon solar cell is from $300 \mathrm{~nm}$ to $1200 \mathrm{~nm}$, light in this wavelength range will produce photovoltaic effect to realize the conversion of light energy into electrical energy. While, the light energy will be reduced by the interface change and the light absorption of each layers of encapsulation material. So the light transmission rates of encapsulating materials have remarkable influence on the optical loss of PV module.

\footnotetext{
* Corresponding author: Zuo Yan: 106779601@qq.com
} 


\subsubsection{Power gain effect of PV encapsulating materials}

Super white low iron embossed tempered glass commonly used in PV module encapsulation. Because of lower iron content and the embossed surface structure, tempered glass of this kind can enhance the transmission efficiency of sunlight in $300 \mathrm{~nm} \sim 1200 \mathrm{~nm}$ [2]. Previous research shows that the sunlight intensity on the solar cells in PV module is about 1.0395 1.0575 times than on the solar cells in open air. So, the encapsulating materials have power gain effect on PV module. The PV module short circuit current is increased by $3 \sim 4$ times than that of solar cell [3].

\subsubsection{Effect of improved PV encapsulating materials}

\subsubsection{Coated glass}

Coated glass is the tempered glass with nano- $\mathrm{SiO}_{2}$ antireflection film, which can increase the transmittance of sunlight in the range of response spectrum. The transmittance of conventional super white low iron emboss tempered glass is about $92 \%$, while the transmittance of coated tempered glass can reach $96 \%$ [4]. Coated tempered glass can increase the power out of PV module by $1.5 \%$ to $2 \%$ times.

\subsubsection{Effect of low cut-off EVA film and high sheet resistance cells}

Because of the different product formulations, especially the content of ultraviolet absorption, there are differences in the transmittance of different EVA films. The cut-off wavelength of the high cut-off EVA film is about $380 \mathrm{~nm}$, while the cut-off wavelength of the low cut-off EVA film is about $280 \mathrm{~nm}$. Using the low cut-off EVA film can increase the power output.

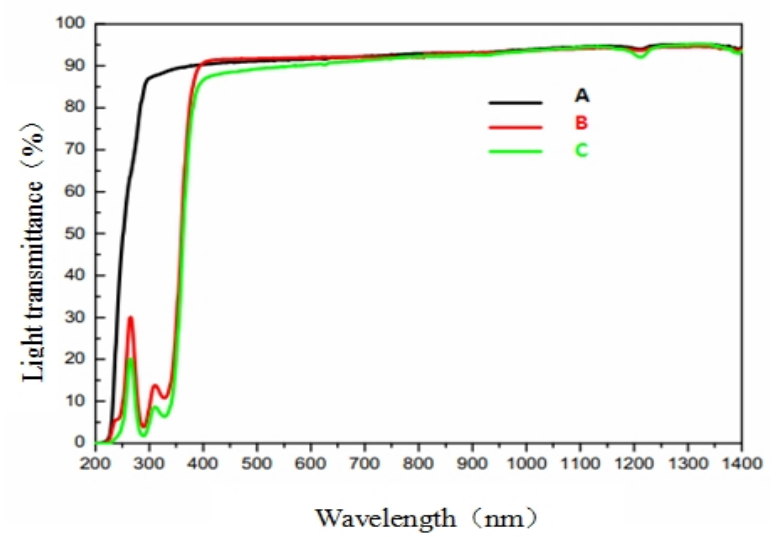

Fig. 3. Light transmittance of different EVA

The transmittance of different EVA films is shown in Fig.3. There is a great transmittance difference in wavelength of $200 \mathrm{~nm} \sim 400 \mathrm{~nm}$ among low and high cutoff EVA films. While the low cut-off EVA film can also accelerate the aging of back sheet, so the high cut-off EVA film also needs to be used in back of the solar cell strings to protect the back sheet aging by ultraviolet rays. The combination of high and low cut-off EVA film can increase the power output by about $0.8 \%[5]$.

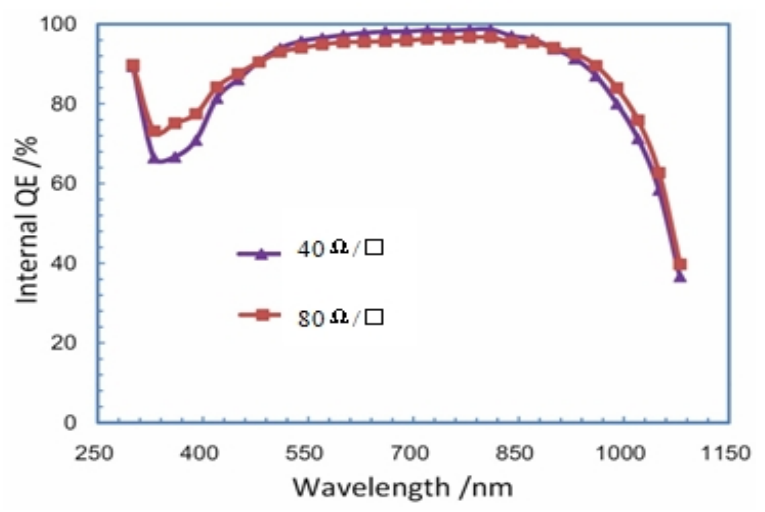

Fig. 4. Internal quantum spectrum of cells

The effect of low cut-off EVA film can be fully embodied with the combination of high sheet resistance cells. The higher of the sheet resistance is the better response of cells are in short wavelength. As shown in Fig.4, the response of high sheet resistance solar cells is much better than that of low sheet resistance solar cells in wavelength of $300 \mathrm{~nm} 380 \mathrm{~nm}$.

In addition, the solar simulator in the electrical performance measurement also needs to be enhanced when the low cut-off EVA film and high sheet resistance solar cells are used. The solar simulator need to generate short wavelength light about $300 \mathrm{~nm} \sim 380 \mathrm{~nm}$, which can evoke the solar cell power output in short wavelength. Otherwise, the sunlight testing blind zone in short wavelength will increase the power loss of the PV module numerically.

\subsubsection{Other encapsulating materials}

The reflectance of white back sheet in mid and long wavelength $(>500 \mathrm{~nm})$ is commonly about $80 \%$. Although there is difference in reflectance of different white back sheets [6], the reflectance of white back sheet is higher than that of black and transparent back sheet by $1 \sim 2 \%$. The power output can be increased by at least $1 \%$ by using high reflectance white back sheet.

The matching of Silicon nitride coating on the solar cells to EVA film and tempered glass also has effect on power output. The idealized refractive index of Silicon nitride is about 2.2, the refractive index EVA film and tempered glass is about 1.5 [7]. Literature indicates that good matching of Silicon nitride coating to EVA film and tempered glass can increase the antireflection effect and the output of PV module.

The width of interconnection ribbon on the solar cells also has effect on power loss. Decrease the width of interconnection ribbon to the width grid line on the solar cells can reduce the loss of incident light and power loss of PV module. Silvering and rolling groove on the upper surface of interconnection ribbon can reflect part of light back to PV module and increase the power output by $2 \%$.

\subsubsection{Comparison test}


In order to compare the effect of different encapsulating materials on power loss of PV module, comparison tests were conducted. Different kinds of tempered glass and EVA film were used for $\mathrm{P}$ type polycrystalline silicon solar cells with same batch and power level. The PV modules were encapsulated with same equipment and technology. The PV modules are tested with the same solar simulator test under the same conditions. The test results are shown in Table 1.Coated tempered glass, low cut-off EVA film and high cut-off EVA film are both used in same PV modules in case 1. While, only high cut-off EVA film and ordinary tempered glass are used in PV modules of case 2 .

Table 1. Power loss comparison of PV modules with different encapsulating materials.

\begin{tabular}{|c|c|c|c|}
\hline Case & $\mathbf{P}_{\text {cell }}$ & $\mathbf{P}_{\text {module(theoretical) }}$ & $\mathbf{P}_{\text {max module (test) }}$ \\
\hline 1 & $4.234 \mathrm{~W}$ & $254.04 \mathrm{~W}$ & $253.213 \mathrm{~W}$ \\
\hline 2 & $4.234 \mathrm{~W}$ & $254.04 \mathrm{~W}$ & $247.516 \mathrm{~W}$ \\
\hline Case & Vmpp & Impp & Power loss \\
\hline 1 & $30.231 \mathrm{~V}$ & $8.411 \mathrm{~A}$ & $0.325 \%$ \\
\hline 2 & $30.283 \mathrm{~V}$ & $8.173 \mathrm{~A}$ & $2.57 \%$ \\
\hline
\end{tabular}

\subsection{Electrical power loss during encapsulation}

\subsubsection{Mismatch power loss $P 1$}

The output current PV module is limited by the lowest solar cell current at the maximum power (Impp). The inconformity of solar cell current will led mismatch in the series connection. In order to reduce this mismatch, two-stage selection is used in the selection of solar cells. First selection is controlled by power output and second selection is controlled by Impp.

\subsubsection{Power loss of series resistance of the interconnection solder ribbon P2}

There are three parts in the power loss of series resistance of the interconnection solder ribbon. The first part $\left(p_{1}\right)$ is made by the ribbon that is not welded with solar cells. The second part $\left(p_{2}\right)$ is made by the ribbon that is welded with solar cells. The third part $\left(p_{3}\right)$ is made by the contact resistance of the ribbon and solar cells. The third part $\left(p_{3}\right)$ is usually no more than $0.1 \mathrm{~W}$ and ignored.

As to three-gird line solar cells, each interconnection solder ribbon carries one third of the total current. Set the electrical resistivity of interconnection solder ribbon is $r_{l}$, the length of the ribbon that is not welded with solar cells is $l$. The length of ribbon that is welded with solar cells consist both front and back ribbon of solar cells. The current and power loss increases with the length of ribbon. Power loss of series resistance of the interconnection solder ribbon can be calculated as follows.

$$
\begin{aligned}
& p_{1}=l r_{1} \times\left(I_{m p p} / 3\right)^{2} \times 6 \times 10 \\
& p_{2}=\left(l_{f}+l_{b}\right) \times r_{1} \times\left(I_{m p p}\right)^{2} / 9 \\
& \mathrm{P} 2=p_{1}+p_{2}+p_{3}
\end{aligned}
$$

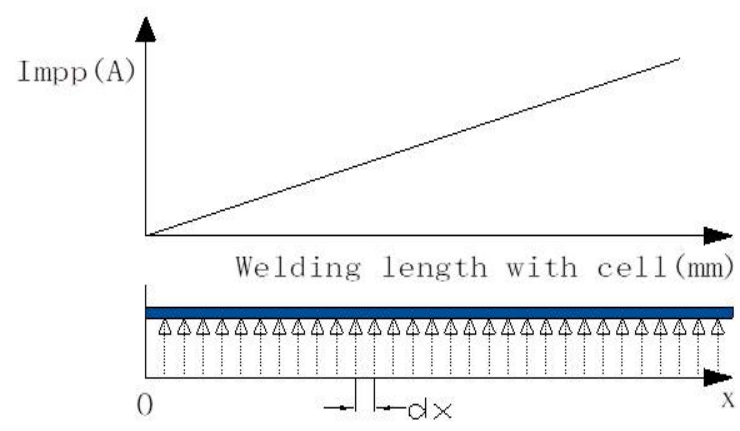

Fig. 5. Current in interconnection solder ribbon

\subsubsection{Power loss of series resistance of the bus solder ribbon $P 3$}
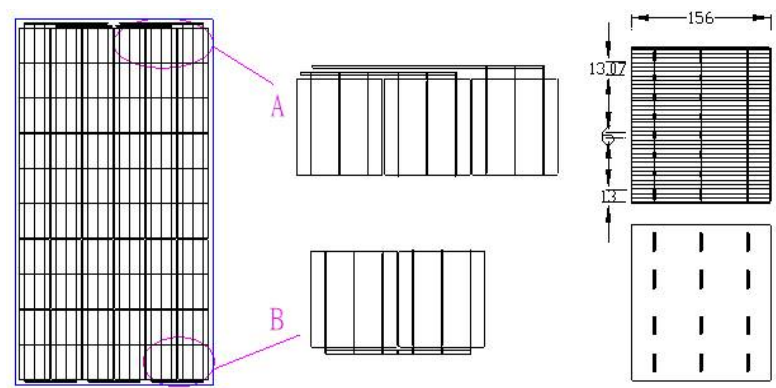

Fig. 6. Connections of bus solder ribbon in PV module

Bus solder ribbon can derive the current in PV module. The bus solder ribbon can be divided into three parts (as shown in Fig.6). Each part carries 1/3, 2/3and 3/3 of the total current respectively. Set the electrical resistivity of bus solder ribbon is $r_{2}$, the length of the three parts of bus solder ribbon $l_{1}, l_{2}$ and $l_{3}$ respectively. Power loss of series resistance of the bus solder ribbon can be calculated as follows.

$$
\mathrm{P} 3=l_{1} r_{2} \times\left(I_{m p p} / 3\right)^{2}+l_{2} r_{2} \times\left(2 I_{m p p} / 3\right)^{2}+l_{3} r_{2} \times\left(I_{m p p}\right)^{2}
$$

\subsubsection{Power loss of the resistance of junction-box P4}

The resistance of junction-box includes line and body resistance. Set the resistance of junction-box is $R_{3}$. Power loss of the resistance of junction-box can be calculated as follows.

$$
\mathrm{P} 4=R_{3} \times\left(I_{m p p}\right)^{2}
$$

\subsubsection{Case study}


Take the case $1 \mathrm{PV}$ module in Table 1 as an example to calculate the electrical power loss. Because of the coated glass and low cut-off EVA film, there are about $6 \%$ power gains of encapsulating materials. So the electrical power loss PE can be calculated as follows.

$\mathrm{P}_{\mathrm{E}}=4.234 \mathrm{~W} \times 60 \times 1.06-253.213 \mathrm{~W}=16.069 \mathrm{~W}$

The electrical parameters are as follows:

a. Mismatch of the solar cells:

$\Delta \mathrm{I}=0.1 \mathrm{~A}, \mathrm{Vmpp}=30.231 \mathrm{~V}$;

b. Interconnection solder ribbon not welded:

$r_{l}=0.0225 \mathrm{~m} \quad \Omega \quad / \mathrm{mm}, \quad l=273 \mathrm{~mm}$ (one cell), Impp $=8.411 \mathrm{~A}$

c. interconnection solder ribbon welded:

$l_{f}=25920 \mathrm{~mm}, l_{b}=12960 \mathrm{~mm}$

d. bus solder ribbon:

$r_{2}=0.0220 \mathrm{~m} \Omega / \mathrm{mm}, l_{1}=l_{2}=624 \mathrm{~mm}, l_{3}=1078 \mathrm{~mm}$

e. resistance of junction box:

$R_{3}=10.5 \mathrm{~m} \Omega$;

All parts of the electrical power loss can be calculated according to the parameters and the results are shown in Table 2.

Table 2. Electrical power loss.

\begin{tabular}{|c|c|c|c|c|}
\hline & \multirow{2}{*}{ P1 } & \multicolumn{3}{|c|}{ P2 } \\
\cline { 3 - 5 } & & $\boldsymbol{p}_{1}$ & $\boldsymbol{p}_{2}$ & $\boldsymbol{p}_{3}$ \\
\hline Power loss (W) & 3.023 & 2.897 & 3.023 & 2.897 \\
\hline Loss ratio (\%) & $19.18 \%$ & $18.39 \%$ & $19.18 \%$ & $18.39 \%$ \\
\hline & $\mathbf{P 3}$ & $\mathbf{P 4}$ & \multicolumn{2}{|c|}{ SUM } \\
\hline Power loss (W) & 2.217 & 0.743 & 15.756 \\
\hline Loss ratio (\%) & $14.07 \%$ & $4.72 \%$ & \multicolumn{2}{|c|}{$100 \%$} \\
\hline
\end{tabular}

The theoretical and calculated electrical power loss is $15.756 \mathrm{~W}$ and $16.069 \mathrm{~W}$ respectively. There is only $0.313 \mathrm{~W}$ 's error between them. The error is only $0.12 \%$ of the power output of the module. Considering the error $( \pm 1 \%)$ of the testing equipment, the calculated electrical power loss has high accuracy and effectiveness.

The calculated results show that the power loss of series resistance of the interconnection solder ribbon plays a dominant role in the total power loss. The mismatch loss and the bus solder ribbon loss each accounts for $15 \%$ of the total electrical power loss. While, the power loss contact resistance of the ribbon and cells is only about $0.1 \%$ and can be ignored.

\subsection{Power loss during working process}

Influenced by the climate and environment, the power output of PV module will decay gradually. This power output decay can be divided into two stages. The first stage is called light induced decay (LID). In the first few days, the power output of PV modules decay greatly and then tends to be stable [8]. The second stage is called aging decay. During the long term service, because of the decay of the solar cells and the encapsulating materials, the power output of PV modules decay slowly.

Solar cell light treatment is used to advance the light induced decay before the encapsulation. As to the aging decay, anti-ultraviolet encapsulating materials can reduce the aging decay of PV module.

\section{Conclusions}

Encapsulating materials have great effect on the power loss of PV module. Improving single encapsulating materials, such as coated tempered glass, low cut-off EVA film and high reflectivity white back sheet have great effect on the power output gain of PV module. In addition, the reduction effect of these encapsulating materials can be superposed nonlinearly.

Improved photovoltaic welding belt can reduce the power loss about $0.8 \sim 1.0 \%$. High transmittance tempered glass can reduce the power loss about $1.5 \sim 2.0 \%$. Improving the reflectance of back sheet can reduce the power loss up to $1 \%$. Low cut-off ethylenevinyl-acetate (EVA) adhesive film can reduce the power loss up to $0.8 \%$. In addition, the reduction effect of these encapsulating materials can be superposed nonlinearly. While, improving the welding quality of solar cells can reduce the optical power loss and electrical power losses at the same time.

As to the electrical power loss, the resistance of the interconnection solder ribbon plays a dominant role. The mismatch loss and the bus solder ribbon loss each accounting for $15 \%$ of the total electrical power loss. While, the power loss contact resistance of the ribbon and cells is only about $0.1 \%$ and can be ignored. So the reduction of the resistance of the ribbon is the key of the reduction of electrical power loss.

\section{References}

1. Chen Zhu, M.S.D. Dissertation Submitted to Shanghai Jiao Tong University, 18 (2013).

2. Xin Chongfei, M.S.D. Dissertation Submitted to South China University of Technology, 18 (2013).

3. Chen Zhu, M.S.D. Dissertation Submitted to Shanghai Jiao Tong University, 31 (2013).

4. Ren Junhai, Standard \& Quality of Light Industry, 33 (2013).

5. Zhao Huali, Technology Wind, 80 (2012).

6. Wang Qi, The 11th China photovoltaic conference and exhibition. 1088 (2011).

7. Wang Xiaoquan, Acta Energiae Solaris Sinica, 341 (2004).

8. Ma Zhiheng, China High-Tech Enterprises,32 (2012). 